Background and aims Global prevalence of obesity has doubled the last 30 years, with WHO estimating that $10 \%$ of men and $14 \%$ of women worldwide are obese. The corresponding health risk is associated with a significant health system cost, loss of health related quality of life, and economic costs such as reduced productivity. Obesity in adulthood is the result of several factors, including weight gain during infanthood. The objective of this paper is to demonstrate the impact on infant weight gain and economic value of low protein nutritional formula compared with standard protein nutritional formula.

Methods A double blind, randomised, controlled trial of 252 healthy infants born of overweight or obese mothers estimated the impact of formula onweight gain up to 36 months. A discrete event simulation estimated the corresponding impact on adult BMI, the incidence of obesity-related diseasesand consequent lifetime changes in health care resources use, health related quality of life (HRQoL), and productivity.

Results Low protein infant formula reduced weight gain at 36 months by $0.31 \mathrm{~kg}$ (from $16.04 \mathrm{~kg}$ with standard formula to $15.74 \mathrm{~kg}$ with low protein formula). The simulation estimates the corresponding changes in the following outcomes over infants' lifetimes: a BMI; incidence of diabetes, stroke, CHD; health care costs, HRQoL and productivity.

Conclusions The use of low protein formula for infants of overweight orobese mothers not only reduces infant weight gain, but also generates lifetime improvements in quality of life, health cost savings and improvements in productivity.

\section{PO-0599 EFFECTS OF NON-NUTRITIVE SUCKING ON GASTROESOPHAGEAL REFLUX IN SYMPTOMATIC PRETERM INFANTS}

L Corvaglia, S Mazzetti, FM Corrado, S Martini, E Mariani, E Legnani, G Faldella. U. O. Neonatologia E Terapia Intensiva Neonatale, Policlinico Sant'Orsola-Malpighi, Bologna, Italy

\subsection{6/archdischild-2014-307384.1239}

Background The therapeutic management of gastroesophageal reflux (GER) in preterm infants still represents a controversial issue among neonatologists. To date, different non-pharmacological strategies, such as body positioning, milk thickening or changes of feeding modalities, have been proposed. However, the effects of non-nutritive sucking (NNS) on GER features, detected by multiple intraluminal impedance (MII), have not yet been evaluated in preterm newborns symptomatic for GER.

Patients and methods Nineteen preterm newborns (GE $\leq 33$ weeks) with GER symptoms underwent a 24-hours pH-MII monitoring. During this period, each infant received eight meals, four followed by NNS, applied by means of pacifier, and four not. Differences in GER features (number of episodes, acidity, duration and height reached) between NNS and non-NNS postprandial periods were evaluated by Wilcoxon signed-rank test.

Results No significant difference in GER features between NNS and non-NNS periods was found. However, postprandial periods without NNS resulted in a slight increase in the mean duration of acid GER episodes (NNS vs. NON-NNS, median values: 51.15 vs. $88.20 \mathrm{sec}, \mathrm{p}$ 0.159). Consequently, during NNS periods the time of esophageal acid exposure was reduced (NNS vs. NON-NNS, median values: 3.54 vs. $6.15 \%, \mathrm{p} 0.171$ ).

Conclusions According to our results, NNS administration during postprandial periods seems to have no significant effects on GER features in symptomatic preterm infants. However, during NNS periods we observed a slight, though not significant,
Abstract P0-0600 Table 1 Influencing factors in unsuccessful breastfeeding first day after delivery

\begin{tabular}{|c|c|c|}
\hline \multicolumn{3}{|l|}{ Factors } \\
\hline & & Epidemiologic \\
\hline Newborn causes & Macro nipple & causes \\
\hline Prematurity & Cosmetic appearance of breast & Age \\
\hline Low birth weight & Drugs & District \\
\hline \multirow[t]{2}{*}{ Oral problem (cleftand lips palate) } & Maternal addiction & Newborn gender \\
\hline & & Sequence \\
\hline Swallowing problem & Maternal stresses & newborn \\
\hline Sleepiness & Cultural causes & Delivery type \\
\hline Unilateral breast suckling & Pacifier usage & \\
\hline Short suckling & Dextrose water feeding & \\
\hline Poor attachment to breast & No belief to colostrums feeding & \\
\hline Maternal causes & Family dispute of parents & \\
\hline Milk insufficiency & Family consults & \\
\hline Inverted nipples & Medical causes & \\
\hline Breast engorgement & Newborn hospitalisation & \\
\hline Nipples fissure & Maternal hospitalisation & \\
\hline Maternal vaginal bleeding & Educational causes & \\
\hline \multicolumn{3}{|c|}{ Breast milk inadequacy thought of } \\
\hline mother & Physiologic delivery training & \\
\hline & Breastfeeding training in room- & \\
\hline Episiotomy pain & ing in & \\
\hline Caesareans section incision pain & Academic graduate level & \\
\hline
\end{tabular}

reduction in the duration of acid GER, which plays a relevant role in the development of GERD. Further larger evaluations are needed to eventually confirm these preliminary data.

\section{PO-0600 ASSESSMENT OF UNSUCCESSFULL MATERNAL BREASTFEEDING FACTORS IN FIRST DAY AFTER DELIVERY}

${ }^{1}$ A Mortazavi, ${ }^{2} \mathrm{M}$ Moharramnejadifard. ${ }^{1}$ Neonatal Ward, Social Security Organization, Zanjan, Iran; ${ }^{2}$ Rooming in Ward, Social Security Organization, Zanjan, Iran

\subsection{6/archdischild-2014-307384.1240}

Background and aims In this research we study the preventive factors in successful breastfeeding in first day after delivery.

Methods and materials This research type was observational descriptive case series. It takes from august 2013 to February 2014. Our target populations were 387 and contain every delivered mother with breastfeeding problems in first day after delivery. For every mother unsuccessful breastfeeding factors as table1 determined and data analysed with SPSS type 20 software and assessed with pearson's correlation and linear regression.

\begin{tabular}{llll}
\multicolumn{5}{l}{$\begin{array}{l}\text { Abstract PO-0600 Table } 2 \\
\text { factors influencing correlation }\end{array}$} \\
\multicolumn{5}{c}{ Standardised Coefficients } \\
confidence level & Sig. & (Beta) & causes \\
$100 \%$ & .000 & .400 & Newborn causes \\
$100 \%$ & .000 & .426 & Environment and Hospital causes \\
$100 \%$ & .000 & .744 & Maternal causes \\
$98.6 \%$ & .014 & -.064 & Cultural causes \\
$94.6 \%$ & .054 & .047 & Educational causes \\
$93 \%$ & .699 & -.009 & Epidemiologic causes \\
\hline
\end{tabular}

